\title{
Um caso clínico de encefalite paraneoplásica
}

Cátia Filipa Neto da Silva, ${ }^{1}$ Filipe Daniel Cunha Costa, ${ }^{1}$ Mário Rui Portilha Antunes da Cunha ${ }^{2}$

\section{RESUMO}

Introdução: A encefalite é uma condição inflamatória cerebral com múltiplas etiologias. Na maioria dos casos, os agentes virais são os principais responsáveis, mas raramente a etiologia pode ser autoimune/paraneoplásica. A incidência de encefalite paraneoplásica é desconhecida. As neoplasias mais frequentemente associadas a esta síndroma são o carcinoma pulmonar, tumor testicular, neoplasia da mama, timoma e linfoma de Hodgkin. Pensa-se que o mecanismo etiopatogénico se relaciona com a produção de autoanticorpos contra a superfície neuronal e/ou proteínas sinápticas. Dependendo do local do sistema nervoso afetado, a sintomatologia varia, sendo que a encefalite límbica é caracterizada pelo início agudo de alterações do comportamento, humor, memória a curto-prazo e disfunção cognitiva. A deteção e tratamento precoces melhoram o prognóstico, a rapidez da recuperação e reduzem o risco de recaída. A ausência de tratamento pode evoluir para um quadro neurológico debilitante, culminando em coma e morte em alguns doentes.

Descrição do caso: Mulher de 50 anos, avaliada na Unidade de Saúde Familiar (USF) em 2017, por alterações mnésicas súbitas e alterações do comportamento. À avaliação apresentava apatia, anedonia e escassez de discurso, esboçando, por vezes, um riso inapropriado. Desorientação espacial, temporal e em relação a si própria, que evoluiu para um quadro de agressividade e não reconhecimento dos seus familiares. A investigação etiológica concluiu tratar-se de encefalite autoimune/paraneoplásica, tendo a doente sido internada em neurologia. $O$ estudo investigacional mostrou massa no mediastino anterior, compatível com timoma. Em 2018, a doente foi submetida a exérese da neoplasia com recuperação do quadro neurológico.

Comentário: A baixa prevalência desta patologia e o seu diagnóstico diferencial com doença psiquiátrica tornam difícil o diagnóstico desta síndroma. O médico de família, conhecendo os seus pacientes ao longo do tempo, está numa posição privilegiada para a deteção de sinais de alarme que carecem de investigação e tratamento diferenciados.

Palavras-chave: Encefalite; Síndroma paraneoplásico; Memória de curto-prazo; Timoma.

\section{INTRODUÇÃO}

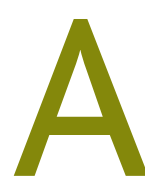

encefalite é uma condição inflamatória do cérebro com múltiplas etiologias. Habitualmente, a causa é infeciosa, sendo que $20-50 \%$ dos casos são atribuíveis a infeções víricas. A infeção pelo Herpes Simplex Vírus (HSV) corresponde a 50-75\% dos casos de encefalite vírica, com uma incidência de um caso em 1.000.000/ano, sendo que o vírus da Varizela-Zoster, enterovírus e arbovírus contribuem para os restantes casos de encefalite vírica. ${ }^{1} \mathrm{Con}$ tudo, a encefalite pode ter etiologia não infeciosa, como a encefalite autoimune/paraneoplásica. ${ }^{2-3}$

A incidência de encefalite paraneoplásica (EPN) é desconhecida, mas estima-se que afete $0,4 \%$ dos doen-

1. Médico Interno de Medicina Geral e Familiar. USF S. Nicolau, ACeS do Alto Ave. 2. Médico Especialista em Medicina Geral e Familiar. USF S. Nicolau, ACeS do Alto Ave. tes com carcinoma brônquico e menos de um em dez mil dos pacientes diagnosticados com neoplasia. ${ }^{2-4} \mathrm{~A}$ doença ocorre devido a uma reação autoimune dirigida contra os antigénios da superfície neuronal ou proteínas sinápticas.

AEPN pode-se manifestar como uma encefalite límbica ou do tronco cerebral, ou ainda ser parte de um envolvimento difuso do neuro-eixo. ${ }^{2-3,5} \mathrm{~A}$ apresentação clínica dependerá da distribuição da condição inflamatória multifocal. A encefalite límbica é caracterizada habitualmente pelo início agudo ou subagudo de alterações comportamentais e do humor, alterações da memória a curto-prazo, convulsões parciais complexas e disfunção cognitiva. ${ }^{5}$ Os sintomas tipicamente desenvolvem-se ao longo de dias a semanas, mas apresentações mais indolentes, ao longo de meses, também já foram descritas. Dependendo da distribuição da condi- 
ção inflamatória no neuro-eixo, outras manifestações podem ocorrer, como convulsões, distúrbios neurológicos focais (afasia, fraqueza muscular ou parestesias), diplopia, disartria, diminuição da acuidade auditiva, disfagia, entre outras. ${ }^{2-4}$

As manifestações neurológicas precedem, em semanas a meses, o diagnóstico de neoplasia em $80 \%$ dos casos. ${ }^{2-3}$ As neoplasias mais frequentemente associadas são o carcinoma do pulmão de pequenas células ( $80 \%$ dos casos), mas também seminoma e outros tumores testiculares, timoma, cancro da mama e linfoma de Hodgkin. ${ }^{2-3}$

A avaliação do líquido cefalorraquidiano (LCR) mostra anomalias, como pleocitose linfocítica ligeira a moderada, elevação modesta das proteínas (<100mg/dL), níveis elevados de IgG e/ou bandas oligoclonais, o que sugere um processo inflamatório. Apesar de a ressonância magnética nuclear (RMN) não ser sensível nem específica pode mostrar sinais característicos, nomeadamente hiperintensidades, nas imagens ponderadas em T2, nas regiões afetadas, como o lobo temporal medial e tronco cerebral, sendo que também podem estar afetadas as regiões subcorticais e o cerebelo..$^{2-3} \mathrm{O}$ eletroencefalograma (EEG) poderá mostrar anomalias não-específicas, como uma lentificação focal ou generalizada, atividade epileptiforme e descargas epileptiformes periódicas lateralizadas. ${ }^{2}$

Apesar de os doentes com EPN serem severamente afetados, habitualmente respondem à terapêutica imunossupressora e à terapêutica dirigida à neoplasia. $\mathrm{O}$ tratamento precoce melhora o prognóstico, a rapidez da recuperação e reduz o risco de recaída, daí a importância de um diagnóstico atempado. ${ }^{6}$

A ausência de tratamento pode levar a uma deterioração neurológica progressiva, culminando em coma e morte em alguns doentes..$^{2-3,6}$

Este relato aborda um caso clínico de encefalite paraneoplásica, com o intuito de alertar a comunidade médica para a sua existência, sintomatologia associada, exames complementares de diagnóstico e prognóstico da doença.

\section{DESCRIÇÃO DO CASO}

Este caso clínico remete-se para uma doente do género feminino, 50 anos de idade, casada. Vive com o marido e dois filhos. Brunideira de profissão, $4^{\circ}$ ano de escolaridade.
Como antecedentes pessoais, apresentava patologia depressiva diagnosticada em 2015. Sem medicação habitual. Sem alergias conhecidas. Sem hábitos etílicos ou tabágicos. Sem antecedentes familiares de demência ou doença psiquiátrica.

Em 21/06/2017, a doente recorreu à consulta aberta da Unidade de Saúde Familiar (USF), acompanhada pelo marido, que se mostrava muito preocupado, referindo alterações mnésicas e do comportamento da cônjuge. Há cerca de três dias, estariam na casa de uma cunhada, quando a doente subitamente se isolou da restante família, passando o dia inteiro sozinha e mostrando uma apatia aquando da abordagem do marido e restantes familiares. Nas duas semanas prévias, as colegas de trabalho também teriam notado uma alteração do comportamento da paciente, com esquecimentos frequentes (local do estacionamento do carro, data de aniversário dos filhos, a sua própria idade) e um maior isolamento social.

A doente não apresentava febre, perda ponderal, episódios infeciosos prévios, sintomatologia respiratória, gastrointestinal ou genitourinária. Sem história de traumatismo. Também não tinha realizado viagens recentes, nem apresentava conviventes doentes.

Ao exame objetivo, esta mostrava-se indiferente, com apatia, anedonia e escassez de discurso, esboçando por vezes um sorriso inapropriado. Humor neutro, sem ideação suicida ou sintomas heterólogos. Desorientada no espaço, tempo e em relação a si própria (não se recordava da sua idade). Também não se recordava da idade dos filhos, do seu estado civil e se os pais já tinham falecido.

A doente apresentava-se hemodinamicamente estável, apirética e eupneica a ar ambiente. Sem alterações dignas de registo no exame físico, apresentando, ao exame neurológico, reflexo pupilar direto e consensual preservados, oculomotricidade preservada, sem nistagmo, campos visuais por confrontação mantidos, sem desvios da língua à protrusão, força motora da face e dos membros preservada, sem dismetrias na prova dedo-nariz e calcanhar-joelho, teste de Romberg negativo e marcha normal.

Realizou-se o Mini-Mental State Examination (MMSE), com um resultado de 18 pontos e, portanto, sugestivo de défice cognitivo.

Nesta fase poderiam ser consideradas, como hipóteses de diagnóstico, a lesão aguda do sistema nervoso 
central (como o acidente vascular cerebral hemorrágico ou isquémico), exacerbação da patologia psiquiátrica de base, o estado confusional agudo (secundário a fármacos ou toxinas), doença neurodegenerativa, neoplasia intracraniana, meningite ou ainda a encefalite. Também seria de considerar a doença de Creutzfeldt-Jakob, uma doença desmielinizante ou inflamatória, a doença de Whipple ou ainda uma encefalopatia metabólica-tóxica.

Neste caso, a presença de antecedentes de patologia depressiva poderia fazer pensar na possibilidade de exacerbação da patologia psiquiátrica de base; contudo, atendendo à instalação súbita e pronunciada dos sintomas, a doente foi encaminhada para o serviço de urgência (SU) para exclusão de outras causas de deterioração cognitiva e alterações do comportamento de novo. A doente foi avaliada por medicina interna, tendo realizado estudo analítico e tomografia axial computorizada crânioencefálica (TAC-CE), que não apresentavam alterações de relevo, com exceção de níveis diminuídos de T4 livre $(0,65 \mathrm{ng} / \mathrm{dL})$ com TSH normal $(0,523 \mathrm{UI} / \mathrm{mL})$.

A doente teve alta para o domicílio, medicada com um suplemento vitamínico. No mesmo dia, o marido recorreu novamente à sua médica assistente na USF, preocupado com o estado clínico da esposa. Desta forma, a doente foi reencaminhada ao SU para avaliação por neurologia, por défice cognitivo agudo de novo. A neurologia considerou "não tratar-se de deterioração cognitiva", tendo a doente sido encaminhada para o SU de psiquiatria. As alterações mnésicas foram enquadradas, assim, no contexto de descompensação aguda de patologia psiquiátrica, tendo a doente sido medicada com alprazolam $0,5 \mathrm{mg}$ duas vezes por dia.

No dia seguinte, por agravamento do quadro de apatia, anedonia e persistência das alterações mnésicas, a doente foi reavaliada pela sua médica assistente na USF, acompanhada pelo marido. Pelo quadro neuropsiquiátrico observado foi introduzida sertralina $50 \mathrm{mg}$, uma vez por dia, com suspensão de alprazolam por agravamento da lentificação psicomotora. A doente foi ainda referenciada com urgência para a consulta externa de psiquiatria e neurologia. Nos dias seguintes, a doente e o marido mantiveram um contacto frequente e regular com a sua médica de família, com uma vigilância clínica a cada 72 horas e uma monitorização dos sinais de alarme, nomeadamente quanto ao aparecimento de alterações da consciência, défices neurológicos de novo, febre ou agravamento do quadro mnésico ou do comportamento.

Ao longo da semana seguinte houve um agravamento progressivo do seu estado neuropsicológico. A doente deixou de fazer as suas tarefas domésticas habituais, como cozinhar e limpar a casa, deixou de reconhecer o marido e os seus filhos e iniciou um quadro de agressividade, recusando-se a tomar banho e a realizar a sua higiene pessoal.

Em 26/06/2017, a doente foi reavaliada pela sua médica de família na USF, com referenciação de novo ao SU.

Foi observada no SU de neurologia onde, por agressividade e agitação psicomotora, foi medicada com clorpromazina intramuscular. Foi repetida TAC-CE, cujo resultado não revelou alterações, e foi ainda realizada punção lombar e EEG (Quadro I). A doente foi medicada empiricamente com aciclovir 750mg.

Atendendo aos resultados foi colocada como hipótese de diagnóstico encefalite de etiologia não esclarecida (autoimune/paraneoplásica), tendo a doente sido internada no serviço de neurologia em 27/06/2017.

Durante o internamento foi efetuado estudo imunológico, pesquisa de anticorpos antineuronais (cujos resultados não foram disponibilizados), ecografia da tiroide (sem alterações de relevo), EEG e RMN-CE (Quadro II).

Ao longo do internamento a doente apresentou períodos de agitação psicomotora, agressividade e desorientação, com múltiplas tentativas de fuga da enfermaria.

Em 12/07/2017 foi instituída imunossupressão com metilprednisolona, sendo que no dia 17 se verificaram melhorias substanciais, com menores períodos de agressividade e melhoria da orientação espaço-temporal.

Entretanto, em 24/07/2017, a paciente iniciou quadro de dor torácica e, por suspeita de tromboembolismo pulmonar, foi realizada TAC toraco-abdomino-pélvica que confirmou tromboembolismo pulmonar bilateral. Foi instituída hipocoagulação em dose terapêutica, mantendo-se a doente hemodinamicamente estável.

Em 25/07/2017 foi realizada tomografia de emissão de positrões (PET) que revelou: "foco de hipermetabo- 


\begin{tabular}{|c|c|}
\hline & Resultado \\
\hline Punção lombar & $\begin{array}{l}\text { - Saída de líquido cefalorraquidiano límpido e gotejante } \\
\text { - Pleocitose com } 29 \text { células (84\% linfócitos, } 11 \% \text { monócitos); 0,69 proteínas } \\
\text { - PCR negativa para citomegalovírus, Herpes Simplex Vírus } 1 \text { e } 2 \text { e vírus da Varizela-Zoster }\end{array}$ \\
\hline Eletroencefalograma & Disfunção cerebral em frontal bilateral e em Fz-Cz, sem registo de atividade epileptiforme \\
\hline
\end{tabular}

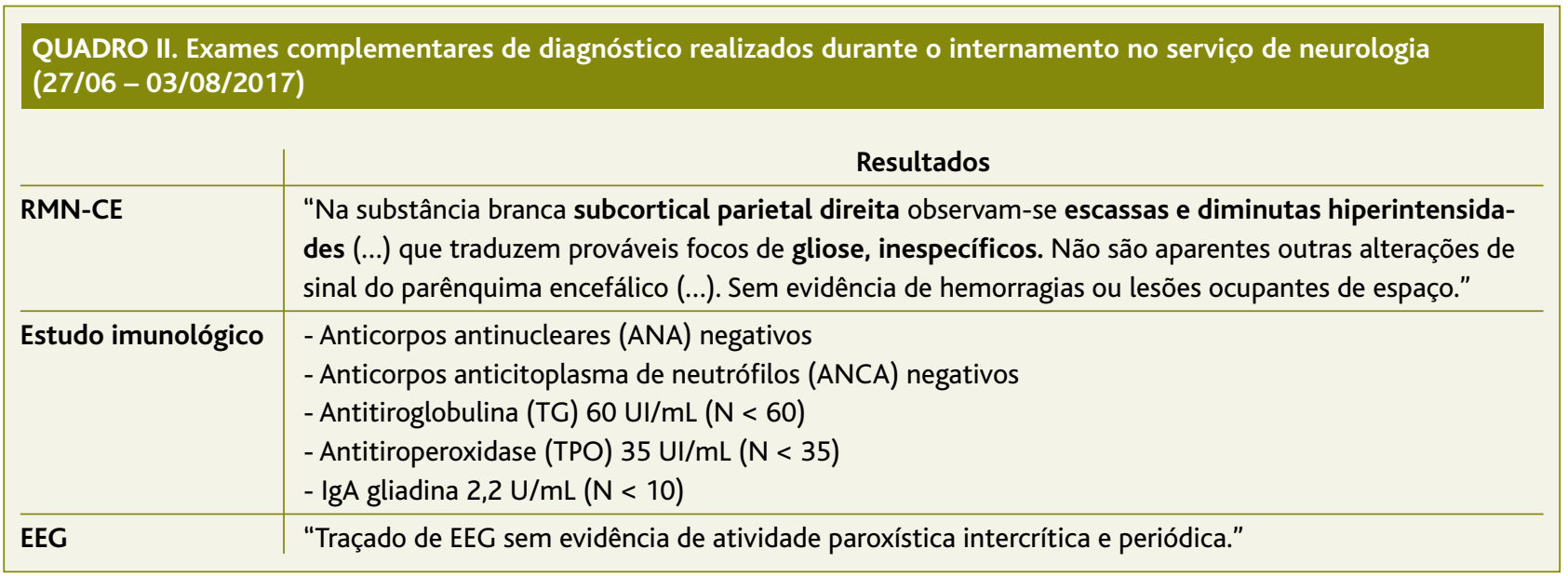

lismo glicolítico ligeiro em massa localizada no mediastino antero-superior à esquerda (...) não podendo excluir-se eventual etiologia maligna."

A doente teve alta em 03/08/2017, com diagnóstico de encefalite paraneoplásica.

À data da alta mostrava melhoria clínica, com resolução quase completa do quadro neurológico, mantendo disforia e desinibição comportamental. Foi orientada para a consulta externa de neurologia, com pedido de RMN torácica e anticorpos antineuronais em curso.

Em 28/09/2017 realizou RMN torácica que mostrou: "lesão nodular arredondada com aproximadamente 33mm de diâmetro no mediastino anterior, superolateralmente ao tronco da artéria pulmonar, em topografia paramediana esquerda, aparentemente bem delimitada, sem sinais de invasão dos grandes vasos mediastínicos demonstrando realce homogéneo (...). Deve-se considerar a possibilidade de uma adenomegalia a mais provável, embora não se possa excluir totalmente a possibilidade de eventual timoma, pelo que se recomenda o estudo complementar por biópsia."
No dia 13/10/2017, a doente foi internada eletivamente para realização de biópsia transtorácica, cujo exame histológico concluiu "que os aspetos observados favorecem fortemente o diagnóstico de timoma".

A doente foi orientada para consulta de cirurgia cardiotorácica, tendo sido submetida a exérese do timoma no dia 11/06/2018, sem complicações. A avaliação histológica da peça anatómica foi compatível com timoma do tipo $\mathrm{AB}$.

No dia $31 / 07 / 2018$, a doente foi observada em consulta programada na USF, mostrando resolução completa da sua sintomatologia, nomeadamente das alterações do comportamento e com recuperação da memória, mantendo amnésia para o período inicial do internamento. Foi reaplicado o MMSE, com um resultado de 26 pontos.

\section{DISCUSSÃO}

Este caso clínico permite alertar para a existência de uma patologia que, apesar da sua raridade, poderá ter importantes implicações na vida do doente, com grave incapacidade neurológica, muitas vezes confundida 
com patologia psiquiátrica. Para além disto, a sua associação com neoplasia, aumenta ainda mais a necessidade de um diagnóstico precoce, sendo o seu tratamento possível e, dependendo do caso, bem-sucedido, como verificado nesta doente.

O timoma é uma neoplasia que se origina nas células epiteliais do timo, um órgão linfoide localizado no mediastino anterior. É a neoplasia mais frequente no mediastino, correspondendo a $25 \%$ dos casos de neoplasias mediastínicas, com um pico de incidência entre a quarta e a quinta décadas de vida. ${ }^{7}$

Cerca de metade dos doentes são assintomáticos, mas os sintomas podem ocorrer como resultado da compressão de estruturas adjacentes com o crescimento tumoral, nomeadamente dispneia, toracalgia, tosse crónica, síndroma da veia cava superior ou disfonia. $^{8}$

Não se sabe a causa desta neoplasia, mas sabe-se que está associada a diversas condições e síndromas neurológicos paraneoplásicos (SNP), sendo a miastenia gravis a mais frequente (em até $40 \%$ dos doentes). ${ }^{9} \mathrm{Ou}-$ tros SNP relacionados com o timoma são a encefalite, polimiosite, síndroma de Morvan, síndroma de Lambert-Eaton e neuromiotonia adquirida, com incidências desconhecidas dada a sua baixa frequência. ${ }^{9}$

A encefalite, no contexto de timoma, poderá manifestar-se sob a forma de alterações da memória e do comportamento, mas também com alucinações, convulsões e alterações do nível de consciência. Habitualmente resulta da produção de autoanticorpos, sendo que o tratamento poderá passar pela imunoglobulina endovenosa, corticoterapia, rituximab ou ciclofosfamida, de acordo com a resposta clínica. A timectomia também poderá trazer benefícios neurológicos a estes doentes.

Não existe uma distinção histológica clara entre timoma benigno ou maligno. A probabilidade do timoma ser maligno é determinada pela sua capacidade de invasão, sendo que os timomas malignos invadem a vasculatura, os ductos linfáticos e as estruturas adjacentes do mediastino. O prognóstico desta neoplasia é pior no caso dos timomas sintomáticos, já que nestes casos maior é a probabilidade de ser maligno, sendo que o fator mais importante no prognóstico é a evidência de invasão na avaliação histológica. ${ }^{7} \mathrm{O}$ tipo de timoma neste caso em particular - tipo $\mathrm{AB}$ - confere um bom prognóstico à doente, com taxas de sobrevivência estimadas aos 10 anos de $100 \% .{ }^{10}$ Contudo, à medida que se verifica a progressão da categoria prognóstica menores são as taxas de sobrevivência, com valores de $28 \%$ aos 10 anos para o timoma do tipo C ou carcinoma tímico. ${ }^{10}$

Neste caso clínico, as manifestações paraneoplásicas precederam o diagnóstico da neoplasia, realçando a importância de um diagnóstico atempado de forma a melhorar o prognóstico, quer da sintomatologia neurológica quer da própria condição oncológica. É importante ainda realçar que a encefalite autoimune/paraneoplásica poderá ter manifestações psiquiátricas precoces e proeminentes, conduzindo à admissão de muitos destes doentes em serviços de psiquiatria, falsamente diagnosticados com doença psiquiátrica. Desta forma, deve prestar-se particular atenção à presença de sinais de alerta que possam sugerir patologia neurológica, nomeadamente a alterações súbitas e severas da função cognitiva, associadas a alterações comportamentais, como observado neste caso, e à presença ou não de défices neurológicos focais objetiváveis ao exame neurológico.

Este caso foi particularmente difícil de gerir, devido à grande carga emocional que trouxe à família, principalmente ao marido, pela severa incapacidade neurológica de que padeceu a sua esposa, mas também pela necessidade de múltiplas idas ao serviço de urgência, até obter um diagnóstico adequado.

O médico de família está numa posição privilegiada, já que conhecendo os seus doentes ao longo do tempo consegue detetar, com uma maior sensibilidade, sinais de alarme ou situações desviantes da normalidade que possam requerer uma avaliação diferenciada e um tratamento especializado. $O$ facto de os cuidados de saúde primários serem o primeiro ponto de contacto com o doente, permitindo uma maior acessibilidade, e a disponibilidade do médico de família para acompanhar os seus doentes em situações de crise, como esta, permitiu levar o caso a bom porto. Assim, o objetivo foi cumprido e a doente recuperou completamente os seus défices neurológicos e a sua qualidade de vida.

\section{REFERÊNCIAS BIBLIOGRÁFICAS}

1. Tyler KL. Acute viral encephalitis. N Eng J Med. 2018;379(6):557-66.

2. Dalmau J, Rosenfeld MR. Paraneoplastic and autoimmune encephali- 
tis. UpToDate [Internet]; 2019 Aug 20. Available from: https://www.uptodate.com/contents/paraneoplastic-and-autoimmune-encephalitis\#H3372498

3. Liebeskind DS. Paraneoplastic encephalomyelitis. Medscape [Internet]; 2016 Sep 9. Avilable from: https://emedicine.medscape.com/article/1157060-overview

4. Said S, Cooper CJ, Reyna E, Alkhateeb H, Diaz J, Nahleh Z. Paraneoplastic limbic encephalitis, an uncommon presentation of a common cancer: case report and discussion. Am J Case Rep. 2013;14:391-4.

5. Gultekin SH, Rosenfeld MR, Voltz R, Eichen J, Posner JB, Dalmau J. Paraneoplastic limbic encephalitis: neurological symptoms, immunological findings and tumour association in 50 patients. Brain. 2000;123(Pt 7):1481-94.

6. Grisold W, Giometto B, Vitaliani R, Oberndorfer S. Current approaches to the treatment of paraneoplastic encephalitis. Ther Adv Neurol Disord. 2011;4(4):237-48.

7. Evans KJ, Miller Q, Kline AL. Thymoma. Medscape [Internet]; 2018 Dec 3. Available from: https://emedicine.medscape.com/article/193809overview

8. Harris C, Croce B, Xie A. Thymoma. Ann Cardiothorac Surg. 2015;4(6): 576.

9. Lancaster E, Evoli A. Paraneoplastic disorders in thymoma patients. J
Thorac Oncol. 2014;9(Suppl 2):S143-7.

10. Evans KJ, Miller Q, Kline AL. Thymoma workup. Medscape [Internet]; 2018 Dec 3. Available from: https://emedicine.medscape.com/article/193809-workup

11. Evans KJ, Miller Q, Kline AL. Thymoma treatment \& management. Medscape [Internet]; 2018 Dec 3. Available from: https://emedicine.medscape.com/article/193809-treatment

12. Meneshian A, Giaccone G, Olivier KR. Clinical presentation and management of thymoma and thymic carcinoma. UpToDate [Internet]; 2019 Nov 21. Available from: https://www.uptodate.com/contents/clinicalpresentation-and-management-of-thymoma-and-thymic-carcinoma

\section{CONFLITO DE INTERESSES}

Os autores declaram não ter quaisquer conflitos de interesse.

\author{
ENDEREÇO PARA CORRESPONDÊNCIA \\ Cátia Filipa Neto da Silva \\ E-mail: catianetosilva@gmail.com \\ https://orcid.org/0000-0002-1832-9803
}

Recebido em 22-09-2018

Aceite para publicação em 28-06-2019

\section{ABSTRACT}

\section{A CLINICAL CASE OF PARANEOPLASTIC ENCEPHALITIS}

Introduction: Encephalitis is an inflammatory condition with multiple etiologies. In most cases, the viral agents are mainly responsible, but rarely the etiology can be autoimmune/paraneoplastic. Paraneoplastic encephalitis incidence is unknown. The neoplasms most often associated with this syndrome are pulmonary carcinoma, tumor testicular, breast neoplasm, thymoma, and Hodgkin's lymphoma. It is thought that the etiopathogenic mechanism relates to the production of autoantibodies against the neuronal surface and/or synaptic proteins. Depending on the location of the nervous system affected, the symptoms vary. Limbic encephalitis is characterized by acute onset of changes in behavior, mood, short-term memory and cognitive dysfunction. Early detection and treatment improve the prognosis, the recovery time and reduce the risk of relapse. The absence of treatment may evolve into a debilitating neurological condition, culminating in coma and death.

Case description: A 50-year-old woman was evaluated at the Unidade de Saúde Familiar (USF) in 2017, due to sudden amnesic and behavioral changes. In the evaluation, she presented apathy, anhedonia and a lack of speech, occasionally sketching an inappropriate laugh. She was disoriented in space, time and in relation to herself, evolving into a picture of aggressiveness and non-recognition of her relatives. The etiological investigation concluded that the situation was compatible with autoimmune/paraneoplastic encephalitis, and the patient was admitted to neurology. The investigational study showed a mass in the anterior mediastinum compatible with thymoma. In 2018, the patient underwent excision of the neoplasia, with the recovery of the neurological condition.

Comment: The low prevalence of this condition and his differential diagnosis with psychiatric illness make it difficult to diagnose this syndrome. The family doctor, who knows his patients over time, is in a privileged position for the detection of alarm signs which require differentiated investigation and treatment.

Keywords: Encephalitis; Paraneoplastic syndromes; Memory, short-term; Thymoma. 